\title{
Determination of Composition of Pozzolanic Waste Mixtures with Optimized Compressive Strength
}

\author{
José Vidal Nardi ${ }^{\mathrm{a}, \mathrm{b}, \mathrm{c}_{*}}$, Dachamir Hotza ${ }^{\mathrm{d}}$ \\ ${ }^{a}$ Laboratório Central do Departamento de Estradas de Rodagem, DER/SC \\ ${ }^{\mathrm{b}}$ Centro Federal de Educação Tecnológica de Santa Catarina, CEFET/SC \\ ${ }^{c}$ Programa de Pós-Graduação em Ciência e Engenharia de Materiais, PGMAT/UFSC \\ ${ }^{\mathrm{d}}$ Departamento de Engenharia Química, EQA/UFSC
}

Received: January 28, 2003; Revised: January 6, 2004

\begin{abstract}
The utilization of ceramic wastes with pozzolanic properties along with other compounds for obtaining new materials with cementating properties is an alternative for reducing the environmental pollution. The acceptance of these new products in the market demands minimal changes in mechanical properties according to its utilization. For a variable range of compositional intervals, attempts were made to establish limiting incorporation proportions that assure the achievement of minimum pre-established mechanical strength values in the final product. In this case minimum compressive strength value is $3,000 \mathrm{kPa}$. A simultaneous association of other properties is also possible.
\end{abstract}

Keywords: mixture design, fly ash, lime, mechanical strength

\section{Introduction}

The fly ash from power plants in southern Brazilian, when discharged, has been a serious cause of degradation in the natural environment ${ }^{1}$. Many studies have been made in order to make good use of this industrial waste, especially as an additive in cement and concrete ${ }^{2,3}$. Studies show that is possible to apply mixture design methods for improving mechanical properties of fly-ash cement and concrete $^{4,5}$. In particular, the methodology of response surfaces, using a mixture design of a constrained area in a triangular surface, presented an alternative to develop new pozzolanic products $^{6}$. A response surface is used to illustrate some mathematical function, or to fit a mesh surface through a scatter of 3D data points?

The combination of fly ash with lime and water lead to chemical reactions, which result in a cement formation at room temperature. The mechanical strength of the final product, among other properties, depends basically on the relative amounts of the three components lime, ash and water. The acceptance of these new products in the market demands minimal mechanical strength changes according to its utilization. Therefore, the objective of this paper is to determine the interval variation of each component that as-

*e-mail: nardijv@aol.com

Articles presented at the XV CBECIMAT, Natal - RN, November de 2002. sures that compressive strength value is never lower than the minimal established value in any resulting mixture.

\section{Experimental Procedure}

In this work, laboratorial results of an empiric project were used to build up a triangular surface (as shown in Figs. 1, 2 and 3) representing a ternary mixture. The whole extension of experimental area is not used, due to restrictions in the proportion limits of the components (upper and lower limits of each variable $)^{7}$. Calculations for the mathematical model were performed using the software Statistica (StatSoft, 1999 edition).

Samples were compacted at 1,320 kPa pressure and according to the Brazilian norm DNER-DPT M 48-64, in cylindrical moulds $(10 \mathrm{~cm}$ diameter and $20 \mathrm{~cm}$ height). Samples were further submitted to compression strength tests after 28 days of cure. The compressive strength of the final product must be higher than $3,000 \mathrm{kPa}$.

\section{Results and Discussion}

The analyzed area was from $7.9 \%$ to $25.8 \%$ for lime 
(X), $44.6 \%$ to $67.6 \%$ for fly ash (Y) and $18.3 \%$ to $40.6 \%$ for water $(\mathrm{Z})$. The restrictive conditions of these intervals were obtained by matrix calculations, giving the following equations:

$$
\begin{aligned}
& -0.11278 X+0.05205 Y=0 \\
& 0.16042 X-0.02468 Y=0 \\
& -0.00159 X+0.05590 Y-0.07073 Z=0 \\
& -0.00058 X-0.03782 Y+0.11619 Z=0
\end{aligned}
$$

where $\mathrm{X}+\mathrm{Y}+\mathrm{Z}=1$, as required by the theory of mixture design.

Triangular form representation of compression strength values measured for 15 ternary mixtures is given in Fig. 1, as a function of the components contents. The validity of the regression model of compressive strengths is limited to the shown quadrangular polygon, which corresponds to studied lime-ash-water interval.

Fitting Eq. 5 corresponds to the variation of the compressive strength (s) as a function of pozzolanic mixture proportions, calculated for the original components:

$$
\begin{aligned}
& \mathrm{s}=29.0173 \mathrm{X}-11.8454 \mathrm{Y}-50.6969 \mathrm{Z}-19.7564 \mathrm{XY}+ \\
& 47.4778 \mathrm{XZ}+116.5461 \mathrm{YZ}
\end{aligned}
$$

Figure 2 shows the location of compositions having compressive strength values larger than $3,000 \mathrm{kPa}$. This region lies between the black continuous curve $(2,995 \mathrm{kPa})$ and $\mathrm{AB}$ line and will be named as effective region.

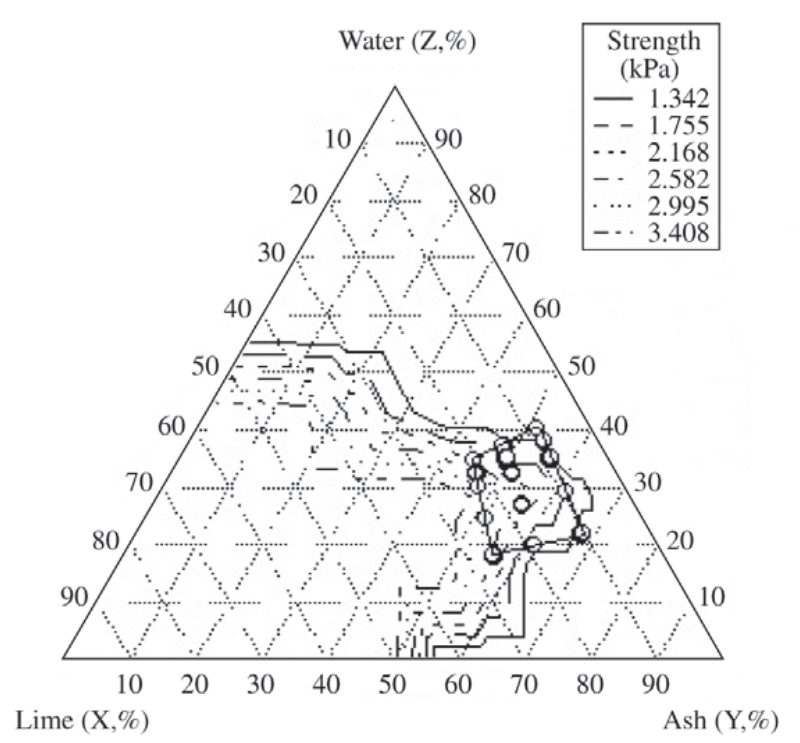

Figure 1. Contour plot of compressive strengths ( $\mathrm{kPa})$ as a function of lime, ash, and water contents.
Other experimental approach was performed to better define the effective region. A new mathematical model was used based on 7 ternary mixtures, and included in the polygonal of that new region. The new analyzed area has the following location: $20.00 \%$ to $23.81 \%$ for lime, $46.16 \%$ to $51.54 \%$ for fly ash, and $26.64 \%$ to $32.51 \%$ for water. The

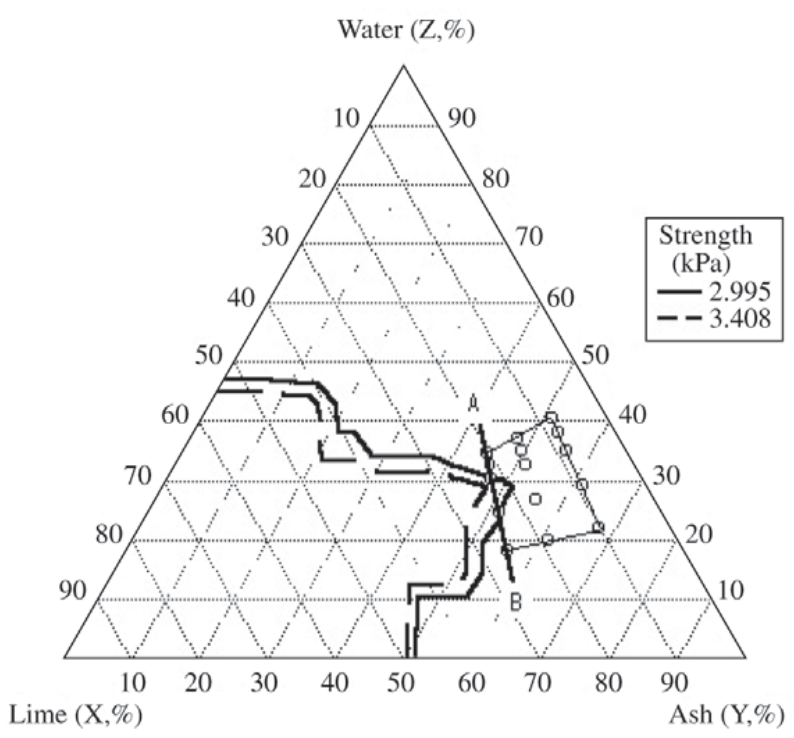

Figure 2. Effective region in which all strength values are higher than $3,000 \mathrm{kPa}$.

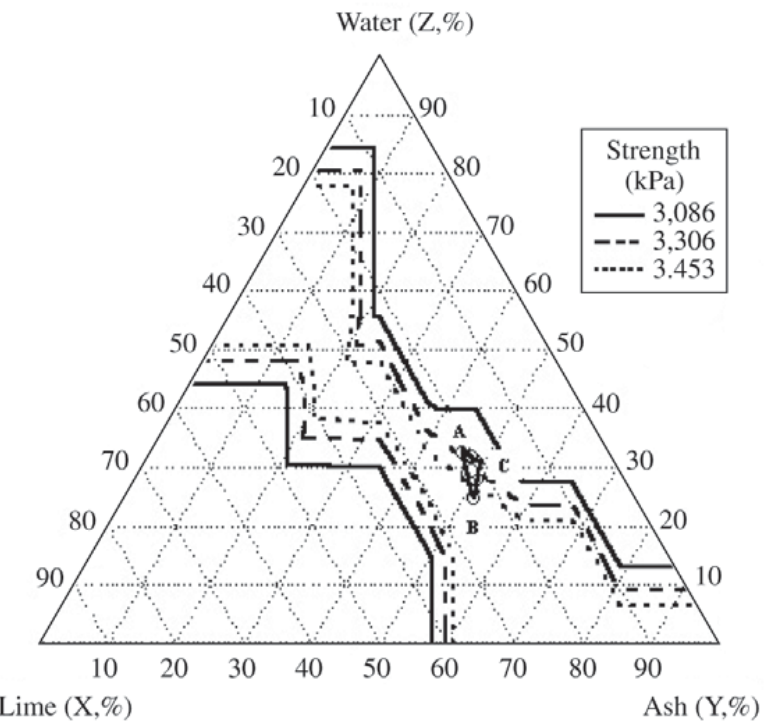

Figure 3. Effective region representation (internal surface ABC triangle) expressed as a function of the new internal restrictions (strength higher than 3,000 kPa). 
restrictive conditions of those intervals imposed by the software, were also obtained by matrix calculation according to the following equations:

$$
\begin{aligned}
& -0.53447859 \mathrm{X}+0.24688142 \mathrm{Y}+0.00142096 \mathrm{Z}=0 \\
& -0.174685436 \mathrm{X}+0.697793598 \mathrm{Y}-0.124462064 \mathrm{Z}=0 \\
& 0.3741977187 \mathrm{X}-0.2392547813 \mathrm{Y}+0.1388652187 \mathrm{Z}=0
\end{aligned}
$$

The results of compression strength tests are presented in Fig. 3, as a function of 7 ternary proportions formed by ABC triangle.

The equation given below corresponds to the compressive strength $\left(\mathrm{s}^{*}\right)$ in the effective region, expressed as a function of the percentages of the pozzolanic mixtures, and calculated by quadratic regression.

$$
\mathrm{s}^{*}=-60,40 \mathrm{X}+4,64 \mathrm{Y}-8,25 \mathrm{Z}+98,23 \mathrm{XY}+
$$$$
145,31 X Z-21,49 Y Z
$$

By analysing Fig. 3 and Eq. 9, it is possible to predict the compositional range that assure minimal mechanical strength changes imposed by the mixtures.

\section{Conclusion}

Mixtures of lime, fly ash and water were found suitable for the production of pozzolanic materials exhibiting high compressive strengths, which can be used in many applica- tions in civil engineering. This is an interesting alternative of using a potentially harmful waste.

Mixture design procedures might constitute interesting approaches to plan and predict the behavior of cementitious materials as a function of the composition. In this work, an effective region was defined in which the amount of each component is established to assure that compressive strength of final product is always higher than a required value.

\section{References}

1. Flues, M.; Hama, P.; Lemes, M.J.L.; Dantas, E.S.K. Atmospheric Environment, v. 36, n. 14, p. 2397-2404, 2002.

2. Adams, L.D. American Ceramic Society Bulletin, v. 59, n. 8, p. 821-821, 1980.

3. Anonimous, ACI Materials Journal v. 84, n. 5, p. 381-409, 1987.

4. Gopalan, M.K.; Haque, M.N. Cement and Concrete Research, v. 19, n.4, p. 634-641, 1989.

5. Tango, C.E.D. An Extrapolation Method for Compressive Strength Prediction of Hydraulic Cement Products, Cement and Concrete Research, v. 28, n.7, p. 969-983, 1998.

6. Nardi, J.V.; Hotza, D. Mixture Design and Response Surface Analysis of Pozzolanic Products, Materials Science Forum, p. 416-418, p. 537-542, 2003.

7. Cornell, J.A. Experiments with Mixtures, Designs, Models and Analysis of Mixtures Data, ed. 2, Wiley, New York, 1990. 
